\title{
Antioxidative and in vitro antiproliferative activity of Arctium lappa root extracts
}

Fabricia S Predes ${ }^{1 *}$, Ana LTG Ruiz², João E Carvalho², Mary A Foglio ${ }^{1}$ and Heidi Dolder ${ }^{1}$

\begin{abstract}
Background: Arctium lappa, known as burdock, is widely used in popular medicine for hypertension, gout, hepatitis and other inflammatory disorders. Pharmacological studies indicated that burdock roots have hepatoprotective, anti-inflammatory, free radical scavenging and antiproliferative activities. The aim of this study was to evaluate total phenolic content, radical scavenging activity by DPPH and in vitro antiproliferative activity of different A. lappa root extracts.

Methods: Hot and room temperature dichloromethanic, ethanolic and aqueous extracts; hydroethanolic and total aqueous extract of $A$. lappa roots were investigated regarding radical scavenging activity by DPPH, total phenolic content by Folin-Ciocalteau method and antiproliferative in vitro activity was evaluated in human cancer cell lines. The hydroethanolic extract analyzed by high-resolution electrospray ionization mass spectroscopy.

Results: Higher radical scavenging activity was found for the hydroethanolic extract. The higher phenolic contents were found for the dichloromethane, obtained both by Soxhlet and maceration extraction and hydroethanolic extracts. The HRESI-MS demonstrated the presence of arctigenin, quercetin, chlorogenic acid and caffeic acid compounds, which were identified by comparison with previous data. The dichloromethane extracts were the only extracts that exhibited activity against cancer cell lines, especially for K562, MCF-7 and 786-0 cell lines.
\end{abstract}

Conclusions: The hydroethanolic extracts exhibited the strongest free radical scavenging activity, while the highest phenolic content was observed in Soxhlet extraction. Moreover, the dichloromethanic extracts showed selective antiproliferative activity against K562, MCF-7 and 786-0 human cancer cell lines.

\section{Background}

Arctium lappa L. (Asteraceae) is a Japanese plant and introduced in Brazil, which is widely used in popular medicine worldwide, as a diuretic and antipyretic tea as well as for hypertension, gout, hepatitis and other inflammatory disorders $[1,2]$. The root has long been cultivated as a popular vegetable for dietary use and folk medicine $[3,4]$. A. lappa tea has become a promising and important beverage, because of ample therapeutic activity [3]. In the literature, many health benefits have been reported due to different classes of bioactive secondary metabolites. These classes include, among others, flavonoids and lignans, for which A. lappa is an important natural source [5]. Pharmacological studies

\footnotetext{
* Correspondence: fpredes@yahoo.com.br

'Department of Anatomy, Cellular Biology, Physiology and Biophysics, Institute of Biology, P.O. Box 6109, University of Campinas, 13083-970,

Campinas, SP, Brazil

Full list of author information is available at the end of the article
}

and clinical trials indicated that burdock roots have hepatoprotective [3,6], anti-inflammatory [7] and free radical scavenging activities $[7,8]$ attributed to the presence of caffeoylquinic acid derivatives [9]. Recently, antiproliferative and apoptotic effects of lignans from A. lappa were described for leukemic cells [10] as well as antitumor effects of arctigenin on pancreatic cancer cell lines [11]. Consumption of dietary antioxidants from plant materials has been associated with lower incidence of diseases due to reduction of oxidative stress. Thus the aim of this study was to determine the total phenolic content by the Folin-Ciocalteau method, to evaluate the the antiradicalar properties based on their ability to quench the stable radical 2, 2-diphenyl-1picrylhydrazyl (DPPH) and in vitro antiproliferative activity of eight different $A$. lappa root extracts. 


\section{Methods}

Plant material

The roots of $A$. lappa (Asteraceae) were collected at CPQBA, University of Campinas (UNICAMP), experimental field (Paulínia, Brazil) in August 2007. Dr. Glyn Mara Figueira was responsible for identification of the plant species. A voucher specimen was deposited at UNICAMP Herbarium under number 146021.

\section{Extraction 1}

Fresh milled roots $(770 \mathrm{~g})$ were extracted successively in a Soxhlet apparatus with dichloromethane, 95\% ethanol and water (2:1 solvent/plant ratio), for 6 hours each solvent. The extracts were concentrated under vacuum (Buchi RE 215) until complete elimination of the organic solvent and subsequently freeze-dried for water elimination, providing dichloromethane (DHE), ethanolic (EHE) and aqueous hot extract (AHE).

\section{Extraction 2}

Fresh milled roots ( $276 \mathrm{~g}$ ) were successively extracted by dynamic maceration with dichloromethane, 95\% ethanol and water (1:5 plant/solvent ratio, 3 times each solvent), at room temperature, in an oscillating agitator (FANEM). The extracts were concentrated under vacuum (Buchi RE 215) until complete elimination of the organic solvent and subsequently freeze-dried for water elimination, providing dichloromethane (DE), ethanolic (EE) and aqueous (AE) extracts.

\section{Extraction 3}

Fresh milled roots (100 g) were extracted three times consecutively in Soxhlet extractor with water (1:5 plant/ solvent ratio). The aqueous extract was freeze-dried, providing the total aqueous extract (TAE).

\section{Extraction 4}

Fresh milled roots $(594 \mathrm{~g})$ were extracted three times with $70 \%$ ethanol (1:5 plant/solvent ratio) under reflux, for 6 hours. The filtrates obtained were combined and concentrated under vacuum. The remaining water was freeze-dried resulting in the hydroethanolic extract (HE).

\section{High-resolution electrospray ionization mass spectrometry (HRESI-MS) of hydroethanolic extract} HRESI-MS was recorded on a Q-Tof Mass Spectrometer (Micromass - U.K.) using direct infusion of a $10 \mu \mathrm{L}$.min$1 \mathrm{MeOH}+0.1 \%$ formic acid solution and ionization by electrospray in the negative ion mode. Major operation conditions were as follows: capillary voltage of $3.5 \mathrm{kV}$, source temperature of $100^{\circ} \mathrm{C}$, desolvation temperature of $100^{\circ} \mathrm{C}$ and cone voltage of $35 \mathrm{~V}$.

\section{2, 2-diphenyl-1-picrylhydrazyl (DPPH) radical scavenging activity}

Microplate DPPH assay was performed as described by Brand-Williams et al. [12], modified by Brem et al. [13]. Briefly, in a 96-well plate, successive sample dilutions $(100 \mu \mathrm{L} /$ well, $0.25,2.5,25$ and $250 \mu \mathrm{g} / \mathrm{mL})$, tested in triplicate, received DPPH solution $(40 \mu \mathrm{M}$ in methanol, $100 \mu \mathrm{L} /$ well) and absorbance was measured at $550 \mathrm{~nm}$ with a microplate reader (VERSA Max, Molecular Devices). Results were determined every 5 min up to $150 \mathrm{~min}$ in order to evaluate the kinetic behavior of the reaction. The percentage of remaining DPPH was calculated as follows: \% DPPH rem $=100 \times([\mathrm{DPPH}]$ sample $/$ [DPPH] blank). A calibrated Trolox standard curve was also made. The percentage of remaining DPPH against the standard concentration was then plotted in an exponential regression, to obtain the amount of antioxidant necessary to decrease the initial DPPH concentration by $50 \%\left(\mathrm{EC}_{50}\right)$. The time needed to reach the steady state for $\mathrm{EC}_{50}$ is defined as $\mathrm{TEC}_{50}$. The antiradical efficiency [14], was calculated as follows: $\mathrm{AE}=1 /\left(\mathrm{EC}_{50} \times \mathrm{TEC}_{50}\right)$.

\section{Total phenolic content}

The total phenolic content was performed as described by Prior et al. [15], with small modifications in order to use a microplate reader. Briefly, an aliquot $(10 \mu \mathrm{L})$ of the sample $(1 \mathrm{mg} / \mathrm{mL})$ was diluted in distilled water $(600 \mu \mathrm{L})$. Then, this solution was applied in a 96-well plate $(150 \mu \mathrm{L}$ per well), in triplicate, and received FolinCiocalteau solution $(12.5 \mu \mathrm{L})$, sodium carbonate $(37.5 \mu \mathrm{L}, 1 \mathrm{M})$ and water $(50 \mu \mathrm{L})$. After incubation at $37^{\circ} \mathrm{C}$ for $2 \mathrm{~h}$, absorbance was measured at $725 \mathrm{~nm}$ with a microplate reader (VERSA Max, Molecular Devices). A calibrated gallic acid standard curve was made and results were expressed as mg equivalents in gallic acid per gram of sample.

\section{In vitro antiproliferative activity assay}

Human tumor cell lines UACC-62 (melanoma), MCF-7 (breast), NCI-ADR/RES (ovarian expressing phenotype multiple drug resistance), 786-0 (renal), NCI-H460 (lung, non-small cells), PC-3 (prostate), OVCAR-3 (ovarian), HT-29 (colon), K562 (leukemia) were kindly provided by Frederick Cancer Research \& Development Center - National Cancer Institute - Frederick, MA, USA. Stock cultures were grown in $5 \mathrm{~mL}$ of RPMI 1640 (GIBCO BRL, Life Technologies) supplemented with 5\% fetal bovine serum. Penicilin: streptomycin $(1000 \mu \mathrm{g} /$ $\mathrm{mL}: 1000 \mathrm{UI} / \mathrm{mL}, 1 \mathrm{~mL} / \mathrm{L})$ were added to the experimental cultures. Cells in 96 -well plates $(100 \mu \mathrm{L}$ cells/well $)$ were exposed to each extract in DMSO $(0.25,2.5,25$ and $250 \mu \mathrm{g} / \mathrm{mL}$ ) at $37^{\circ} \mathrm{C}, 5 \%$ of $\mathrm{CO}_{2}$ for $48 \mathrm{~h}$. The final concentration of DMSO did not affect the cell viability. 
Then, a 50\% trichloroacetic acid solution was added and after incubation $\left(30 \mathrm{~min}\right.$ at $\left.4^{\circ} \mathrm{C}\right)$, washing and drying, cell proliferation was determined by spectrophotometric quantification (540 nm) of cellular protein content using sulforhodamine $\mathrm{B}$ assay. Using the concentrationresponse curve for each cell line the TGI (= concentration that produces total growth inhibition or a cytostatic effect) were determined through non-linear regression analysis using the software ORIGIN 7.5 (OriginLab Corporation) and corresponded to the test extract concentration necessary to inhibit proliferation of the cells.

\section{Results and Discussion}

The yields of the different extraction for A. lappa are listed in Table 1 . The extraction efficiency of the solvents in the successive extractions increased in the order: ethanol > water $>$ dichloromethane. The aqueous and hydroethanolic extraction exhibited the greatest yields.

The phenolic compounds are ubiquitous phytochemicals present in plant foods with various biological activities including antioxidant properties. They exert properties such as free radical scavenging and inhibiting the generation of reactive species $[16,17]$. Phenolic compounds constitute a group of secondary metabolites that are quite widespread in nature with several therapeutical properties $[17,18]$. Their antioxidant activity is mainly due to their redox properties, which allow them to act as reducing agents, hydrogen donors, free radical scavengers, singlet oxygen quenchers and metal chelators [18].

Total phenolic content of all extracts are shown in Figure 1. The present study showed that the highest phenolic compound concentrations were obtained for Soxhlet extraction with dichloromethane $(79.45 \mathrm{mg}$ gallic acid/g extract) and ethanol (77.26 mg gallic acid/g extract) rather than extraction at room temperature. Whereas, the hydroethanolic extract (HE) showed a considerable phenolic content $(72.61 \mathrm{mg}$ gallic acid/g extract). A previous study with $A$. lappa roots reported that the extraction with a chloroform and ethanol (1:1)

Table 1 Yield of the different solvent extractions of $A$. Iappa root

\begin{tabular}{ll}
\hline Extract & Yield \\
\hline Dichloromethane hot extract & $0.12 \%$ \\
Ethanolic hot extract & $6.39 \%$ \\
Aqueous hot extract & $2.87 \%$ \\
Dichloromethanic extract & $0.10 \%$ \\
Ethanolic extract & $4.45 \%$ \\
Aqueous extract & $3.51 \%$ \\
Total aqueous extract & $10.56 \%$ \\
Hydroethanolic extract & $10.25 \%$
\end{tabular}

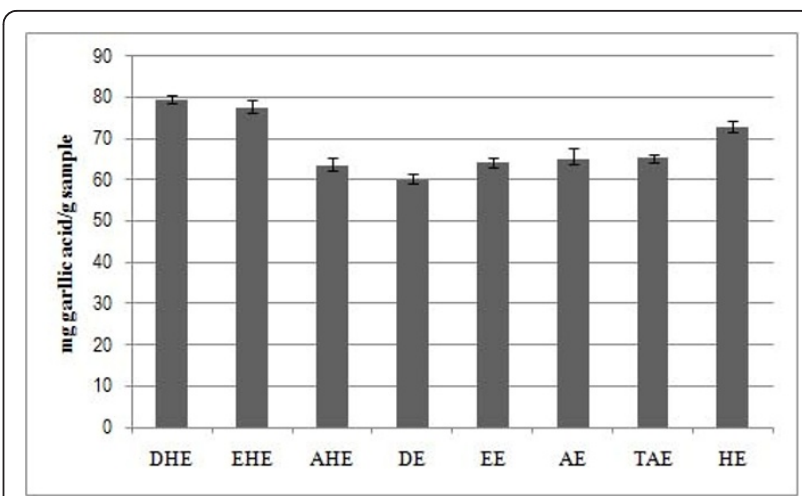

Figure 1 Total phenolic compounds of $A$. lappa extracts. DHE dichloromethane hot extract; EHE: ethanolic hot extract; $\mathrm{AHE}$ : aqueous hot extract; DE: dichloromethane extract; EE: ethanolic extract; AE: aqueous extract; TAE: total aqueous extract; HE:

hydroethanolic extract. The black bars represent standard deviation.

mixture resulted in higher concentration to phenolic compounds $(85.15 \pm 0.55 \mathrm{mg}$ gallic acid/g dry extract), besides a great quantity of flavonoid $(12.57 \pm 0.05 \mathrm{mg}$ quercetin/g extract) in the chloroformic extract; moreover, they reported a phenolic content $(65.92 \pm 0.36 \mathrm{mg}$ gallic acid/g extract) [18] for the ethanol extract which is similar to that described herein. Also, researchers [19] described that Arctium minus ssp minus leaves aqueous extract exhibited a total phenolic content of $58.93 \pm$ $2.72 \mathrm{mg}$ gallic acid/g of extract, while the ethanolic extract gave $48.29 \pm 0.21 \mathrm{mg}$ gallic acid/g of extract.

Many authors have reported a direct relationship between total phenolic content and antioxidant activity in various seeds, fruits and vegetables [20-22]. Antioxidant properties, especially radical scavenging activities, are very important due to the deleterious role of free radicals in foods and in biological systems. The DPPH radical has been widely accepted as a tool for estimating free radical scavenging activities of various compounds and plant extracts $[19,21]$. Although the present study evaluated the scavenging activity of all extracts, only hydroethanolic extract showed strong antiradicalar activity compared to the commercial standards used, licopene and trolox. Table 2 shows the scavenging effect of extracts and reference substances.

The hydroethanolic extract of A. lappa was then analyzed by high-resolution electrospray ionization mass spectroscopy and the presence of quercetin, arctigenin,

Table 2 DPPH radical scavenging of $A$. lappa extract (mean \pm SEM)

\begin{tabular}{lccc}
\hline Sample & $\mathrm{EC}_{\mathbf{5 0}}(\boldsymbol{\mu} \mathbf{g} / \mathbf{m l})$ & $\mathrm{TEC}_{\mathbf{5 0}}(\mathbf{m i n})$ & $\mathrm{AE}$ \\
\hline HE & $4.79 \pm 0.15$ & 5 & $0.0418 \pm 0.001$ \\
Lycopene & $21.28 \pm 0.11$ & 0.1 & $0.47 \pm 0.002$ \\
Trolox & $1.13 \pm 0.1$ & 0.1 & $8.98 \pm 0.84$ \\
\hline
\end{tabular}


Table 3 High-resolution eletrospray ionization mass spectrometry (HRESI-MS) data of Quercetin, Arctigenin, Chlorogenic acid, and Caffeic acid identified in the hydroethanolic extract of Arctium lappa root

\begin{tabular}{ccccc}
\hline Compound & Molecular Formule & Calculated [M-H]- mass & Experimental [M-H]- mass & E (ppm) \\
\hline Quercetin & $\mathrm{C}_{15} \mathrm{H}_{10} \mathrm{O}_{7}$ & 301.0348 & 301.0293 & 18.27 \\
Arctigenin & $\mathrm{C}_{21} \mathrm{H}_{24} \mathrm{O}_{6}$ & 371.1495 & 371.1542 & 12.66 \\
Chlorogenic acid & $\mathrm{C}_{16} \mathrm{H}_{18} \mathrm{O}_{9}$ & 353.0872 & 353.0896 & 6.80 \\
Caffeic acid & $\mathrm{C}_{9} \mathrm{H}_{8} \mathrm{O}_{4}$ & 179.0344 & 179.0305 & 21.78 \\
\hline
\end{tabular}

chlorogenic acid and caffeic acid was demonstrated. These substances were identified by comparison of their calculated and measured high resolution deprotonated mass (Table 3). Phenolic compounds such as chlorogenic acid, caffeic acid [4], and caffeoylquinic acid derivatives [9] were isolated from A. lappa roots. Also, flavonoids such as quercetin and rutin were isolated from leaves [19] and roots [23] of A. lappa. Therefore, antioxidant properties of this plant could be attributed to these compounds. Moreover, Erdemoglu et al [19] reported that $A$. minus leaves aqueous extract had antioxidant activity attributed to flavonoids thus corroborating our results for A. lappa.

The antiproliferative properties of the eight extracts of A. lappa roots were assessed by using nine human cancer cell lines, and the chemotherapeutic drug, doxorubicin, as a positive control. Among all extracts evaluated, dichloromethane extracts were the only ones with antiproliferative activity. The most active extract (DE) presented a moderate activity for all cell lines with selectivity for $\mathrm{K} 562$ $(\mathrm{TGI}=3.6 \mu \mathrm{g} / \mathrm{mL})$ and MCF-7 $($ TGI $=41.1 \mu \mathrm{g} / \mathrm{mL})$ (Table 4) while DHE extract displayed the lowest activity with selectivity for K562 (TGI = $17.0 \mu \mathrm{g} / \mathrm{mL}$ ) and 786-0 $(\mathrm{TGI}=155.7 \mu \mathrm{g} / \mathrm{mL})$ (Table 4$)$. The difference in the antiproliferative effects between hot and room temperature extractions may have resulted from the different bioactive substances contained in the extracts due to the sensitivity to heat treatment. An antiproliferative activity study, using prostate cancer cells ( $\mathrm{LNCaP})$, attributed the inhibitory activity of $A$. lappa seeds hydromethanolic extract to the presence of compounds lappaol A, C and F [24]. A study performed with $A$. lappa showed that dichloromethane seed extract inhibits cancer cell viability under nutrientdeprived conditions, as observed in pancreatic cancer and hepatoma cell lines at $50 \mu \mathrm{g} / \mathrm{ml}$ concentration. The authors also reported the isolation of arctigenin which exhibits cytotoxicity by inducing necrosis in cancer cells
[10]. Researchers [11] also reported that hydromethanolic extract of $A$. lappa fruits shows potent antiproliferative activity against B cell hybridoma cells (MH60) attributed to the presence of arctigenin. Ferracane et al [5] recently isolated arctiin from A. lappa root, which demonstrated, according to other research groups, a strong cytotoxic effect on human hepatoma cell line (HepG2) [25], human lung cancer (A549), human ovarian cancer (K-OV-3), human skin cancer (SK-MEL-2); human CNS cancer (XF498) and human colon cancer (HCT15) [26].

A. lappa is plant popularly used in the diet as a vegetable and in alternative medicine because it has ample therapeutic action. Moreover, this plant is a component of Flor-Essence $^{\circledR}$ and Essiac ${ }^{\circledR}$, which is two of the most widely used herbal products by cancer patients [27-29]. Several experimental studies have shown evidence of biological activity of $A$. lappa extracts or active compounds including antioxidant, anti-inflammatory, free radical-scavenging, antibacterial and hepatoprotective actions [2]. Thus the current study contributes to the growing literature which demonstrates that A. lappa show antioxidant and human tumor cell antiproliferative activities in vitro. Although, several studies demonstrated biological properties of A. lappa in vitro, further research is needed to elucidate the in vivo activities.

\section{Conclusions}

Our results demonstrated that hydroethanolic extracts exhibited the strongest free radical scavenger activity while the highest phenolic content was observed in Soxhlet extraction with dichloromethane, ethanol and hydroethanolic mixture. Moreover, the dichloromethanic extracts are the most important for this research in that they showed selective antiproliferative activity against K562, MCF-7 and 786-0 human cancer cell lines. On the other hand, the hydroethanolic extract had the

Table 4 Tumor growth inhibition (TGI) $(\mu \mathrm{g} / \mathrm{mL})$ induced by A. lappa extracts

\begin{tabular}{|c|c|c|c|c|c|c|c|c|c|}
\hline & $\mathrm{U}$ & $M$ & A & 7 & 4 & $P$ & 0 & $\mathrm{H}$ & $\mathrm{K}$ \\
\hline Doxo & 3,22 & 0,16 & 16,79 & 0,20 & 0,05 & 0,34 & $>25$ & 1,51 & 0,03 \\
\hline DHE & $>250$ & $>250$ & $>250$ & 155,79 & $>250$ & $>250$ & $>250$ & $>250$ & 17,06 \\
\hline $\mathrm{DE}$ & $>250$ & 41,12 & $>250$ & 60,32 & 50,47 & 62,28 & 81,99 & 61,43 & 3,62 \\
\hline
\end{tabular}

$\mathrm{U}=\mathrm{UACC}-62$ (melanoma), $\mathrm{M}=\mathrm{MCF}-7$ (breast), $\mathrm{A}=\mathrm{NCl}-\mathrm{ADR} / \mathrm{RES}$ (expressing multiple drug resistance phenotype), $7=786-0$ (renal), $4=\mathrm{NCl}-\mathrm{H} 460$ (lung, nonsmall cells), $\mathrm{P}=\mathrm{PC}-3$ (prostate), $\mathrm{O}=$ OVCAR-3 (ovarian), $\mathrm{H}=\mathrm{HT}-29$ (colon), $\mathrm{K}=\mathrm{K} 562$ (leukemia). 
greatest yield and shows free radical scavenger activity and high phenolic content, making this extract the best adapted for future "in vivo" studies.

\section{Acknowledgements}

Ms Fabricia de Souza Predes is supported by a scholarship from Fundação de Amparo à Pesquisa do Estado de São Paulo (FAPESP: proc. 2006/06142-8) and by CAPES, an entity of the Brazilian Government for the training of human resources. MAF wishes to thanks CNPq for research fellowship. The Authors thank Prof. Dr. Marcos N. Eberlin and Dr. Regina Sparrapan from Thomson Laboratory from IQ-Unicamp for acquiring HRESI-MS data services and Elaine Cabral.

\section{Author details}

'Department of Anatomy, Cellular Biology, Physiology and Biophysics, Institute of Biology, P.O. Box 6109, University of Campinas, 13083-970, Campinas, SP, Brazil. ${ }^{2}$ CPQBA, P.O. Box 6171, University of Campinas, 13083970, Campinas, SP, Brazil.

\section{Authors' contributions}

FSP: Was responsible for conception and design, acquisition of data, analysis and interpretation of data and drafted the manuscript. MAF: made substantial contribution to conception and design, interpretation of data and revised it critically for important intellectual content. JEC: made substantial contribution to conception and design of the antiproliferative assay, interpretation of data and revised it critically for important intellectual content. ALTGR: made substantial contribution to conception and design of the antiproliferative, DPPH and total phenolic content assay, interpretation of data and revised it critically for important intellectual content. All authors read and approved the final manuscript.

\section{Competing interests}

The authors declare that they have no competing interests.

Received: 7 July 2010 Accepted: 23 March 2011

Published: 23 March 2011

\section{References}

1. Pereira J, Bergamo D, Pereira J, França S, Pietro R, Silva-Sousa Y: Antimicrobial activity of Arctium lappa constituents against microorganisms commonly found in endodontic infections. Braz Dent $J$ 2005, 16(3):192-196.

2. Predes F, Matta S, Monteiro J, Oliveira T: Investigation of liver tissue and biochemical parameters of adult wistar rats treated with Arctium lappa L. Braz Arch Biol Technol 2009, 52(2):335-340.

3. Lin S, Lin C, Lin C, Lin Y, Chen C, Chen I, Wang L: Hepatoprotective effects of Arctium lappa linne on liver injuries induced by chronic ethanol consumption and potentiated by carbon tetrachloride. J Biomed Sci 2002, 9(5):401-409.

4. Chen F, Wu A, Chen C: The influence of different treatments on the free radical scavenging activity of burdock and variations of its active components. Food Chem 2004, 86(4):479-484.

5. Ferracane R, Graziani G, Gallo M, Fogliano V, Ritieni A: Metabolic profile of the bioactive compounds of burdock (Arctium lappa) seeds, roots and leaves. J Pharm Biomed Anal 2010, 51(2):399-404.

6. Lin S, Chung T, Lin C, Ueng T, Lin Y, Lin S, Wang L: Hepatoprotective effects of Arctium lappa on carbon tetrachloride-and acetaminopheninduced liver damage. Am J Chin Med 2000, 28(2):163-173.

7. Lin C, Lin J, Yang J, Chuang S, Ujiie T: Anti-inflammatory and radical scavenge effects of Arctium lappa. Am J Chin Med 1996, 24(2):127-137.

8. Duh P: Antioxidant activity of burdock (Arctium lappa Linne): its scavenging effect on free-radical and active oxygen. J Am Oil Chem Soc 1998, 75(4):455-461.

9. Maruta Y, Kawabata J, Niki R: Antioxidative caffeoylquinic acid derivatives in the roots of burdock (Arctium lappa L.). J Agric Food Chem 1995, 43(10):2592-2595.

10. Awale S, Lu J, Kalauni S, Kurashima Y, Tezuka Y, Kadota S, Esumi H: Identification of arctigenin as an antitumor agent having the ability to eliminate the tolerance of cancer cells to nutrient starvation. Cancer Res 2006, 66(3):1751-1757.

11. Matsumoto T, Hosono-Nishiyama K, Yamada H: Antiproliferative and apoptotic effects of butyrolactone lignans from Arctium lappa on leukemic cells. Planta medica 2006, 72(3):276-278.

12. Brand-Williams W, Cuvelier M, Berset $C$ : Use of a free radical method to evaluate antioxidant activity. LWT-Food Sci Technol 1995, 28(1):25-30.

13. Brem B, Seger C, Pacher T, Hartl M, Hadacek F, Hofer O, Vajrodaya S, Greger $\mathrm{H}$ : Antioxidant dehydrotocopherols as a new chemical character of Stemona species. Phytochemistry 2004, 65(19):2719-2729.

14. Jiménez-Escrig A, Jiménez-Jiménez I, Sánchez-Moreno C, Saura-Calixto F: Evaluation of free radical scavenging of dietary carotenoids by the stable radical 2, 2-diphenyl-1-picrylhydrazyl. J Sci Food Agricul 2000, 80(11):1686-1690.

15. Prior R, Wu X, Schaichs $K$ : Standardized methods for the determination of antioxidant capacity and phenolics in foods and dietary supplements. J Agric Food Chem 2005, 53(10):4290-4302.

16. Zhang Y, Seeram N, Lee R, Feng L, Heber D: Isolation and identification of strawberry phenolics with antioxidant and human cancer cell antiproliferative properties. J Agric Food Chem 2008, 56(3):670-675.

17. Gülçin I: Antioxidant activity of caffeic acid (3, 4-dihydroxycinnamic acid). Toxicology 2006, 217(2-3):213-220

18. Gilioli AMHH, Missau FC, Brighente IMC, Marques MCA, Pizzolatti MG: Avaliação do teor de fenólicos e flavonóides em extratos de Arctium lappa. 30a Reunião Anual da Sociedade Brasileira de Química 2007, 177.

19. Erdemoglu N, Turan N, Akkol E, Sener B, Abacloglu N: Estimation of antiinflammatory, antinociceptive and antioxidant activities on Arctium minus (Hill) Bernh. ssp. minus. J Ethnopharmacol 2009, 121(2):318-323.

20. Carvalho M, Ferreira P, Mendes V, Silva R, Pereira J, Jerónimo C, Silva B: Human cancer cell antiproliferative and antioxidant activities of Juglans regia L. Food Chem Toxicol 48(1):441-447.

21. Gulcin I, Tel A, Kirecci E: Antioxidant, Antimicrobial, Antifungal, and Antiradical Activities of Cyclotrichium Niveum (BOISS.) Manden and Scheng. Inter J Food Prop 2008, 11(2):450-471.

22. Gülçin : The antioxidant and radical scavenging activities of black pepper (Piper nigrum) seeds. Int J Food Sci Nutrit 2005, 56(7):491-499.

23. Scorzoni LBT, Barizan WS, França SC, Pietro RCLR, Januária AH: Estudo fitoquímico de Arctium lappa (Compositae). 30a Reunião Anual da Sociedade Brasileira de Química 2007, 20.

24. Ming D, Guns E, Eberding A, Towers N: Isolation and characterization of compounds with anti-prostate cancer activity from Arctium lappa L. using bioactivity-guided fractionation. Pharmaceutical Biology 2004, 42(1):44-48.

25. Moritani S, Nomura M, Takeda Y, Miyamoto K: Cytotoxic components of bardanae fructus (goboshi). Biol Pharm Bull 1996, 19(11):1515-1517.

26. Ryu S, Ahn J, Kang Y, Han B: Antiproliferative effect of arctigenin and arctiin. Arch Pharm Res 1995, 18(6):462-463.

27. Tai J, Cheung S, Wong S, Lowe C: In vitro comparison of Essiac ${ }^{\circledR}$ and FlorEssence ${ }^{\oplus}$ on human tumor cell lines. Oncol Rep 2004, 11(2):471-476.

28. Tamayo C, Richardson M, Diamond S, Skoda I: The chemistry and biological activity of herbs used in Flor-EssenceTM herbal tonic and Essiac. Phytother Res 2000, 14(1):1-14.

29. Leonard S, Keil D, Mehlman T, Proper S, Shi X, Harris G: Essiac tea: Scavenging of reactive oxygen species and effects on DNA damage. J Ethnopharmacol 2006, 103(2):288-296.

\section{Pre-publication history}

The pre-publication history for this paper can be accessed here: http://www.biomedcentral.com/1472-6882/11/25/prepub

\section{doi:10.1186/1472-6882-11-25}

Cite this article as: Predes et al:: Antioxidative and in vitro antiproliferative activity of Arctium lappa root extracts. BMC Complementary and Alternative Medicine 2011 11:25. 